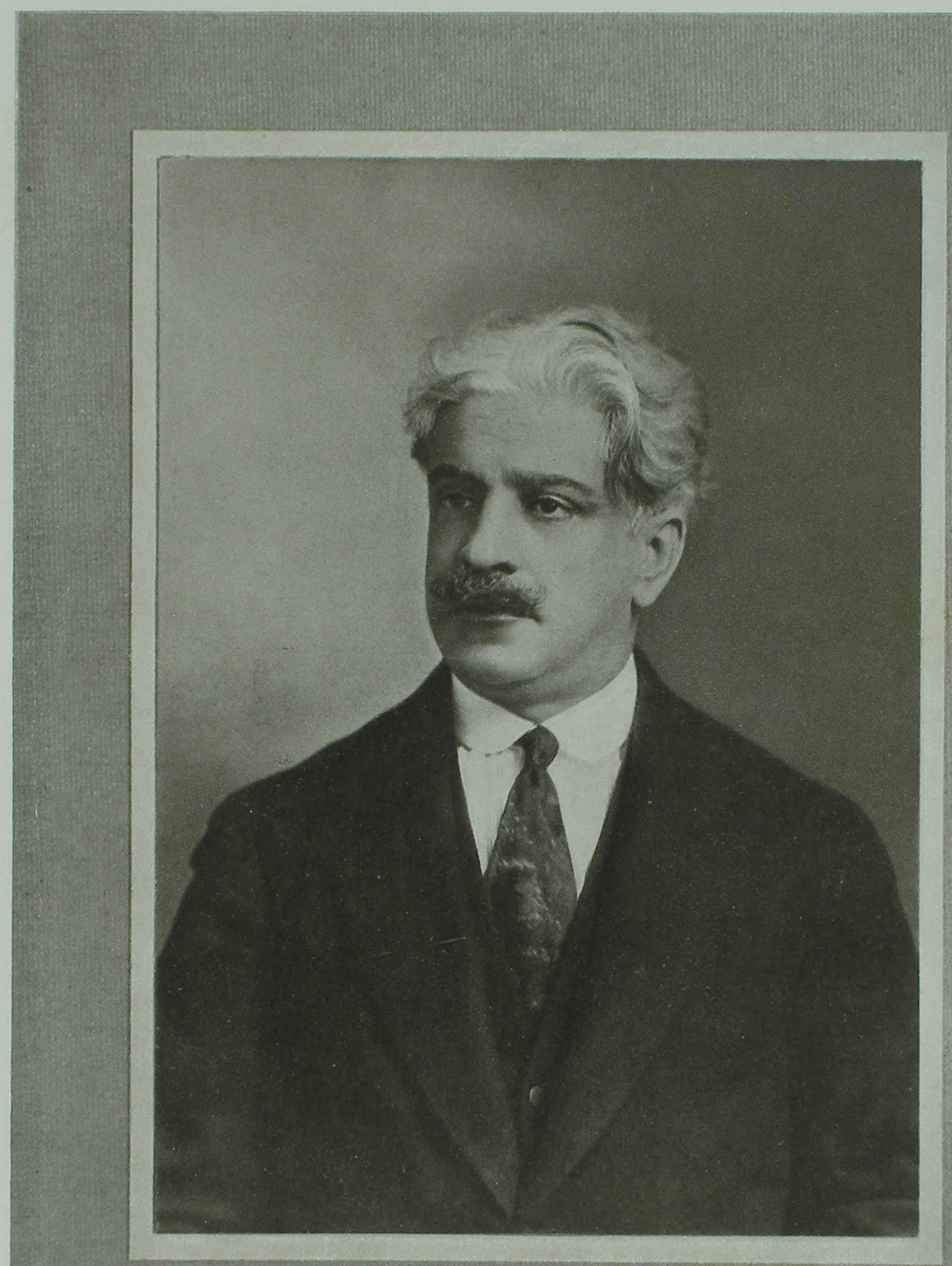

\title{
Oswaldo Cruz
}

Fundador da medicina experimental no Brasil 


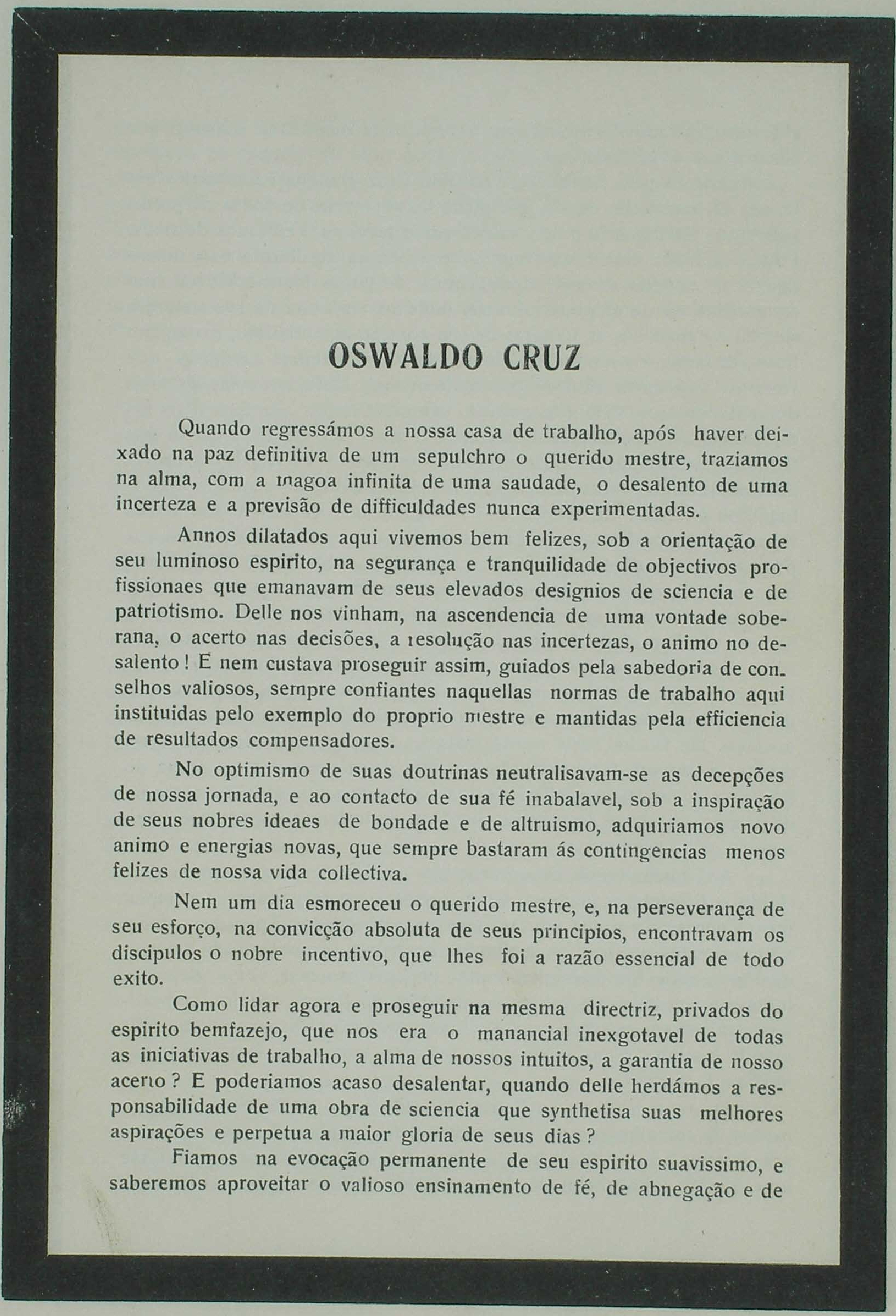




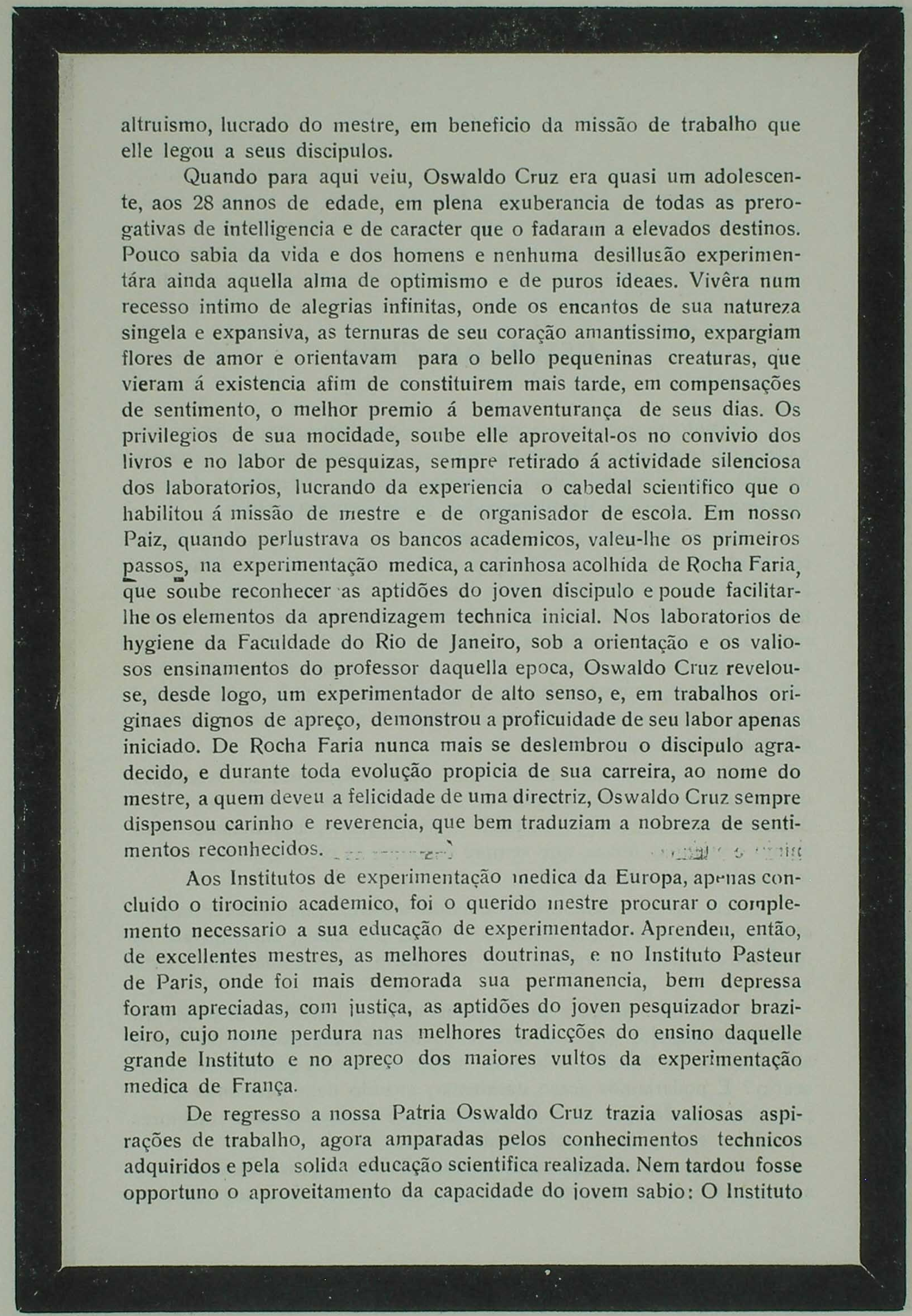


sôro-therapico federal, fundado pelo Barão de Pedro Affonso e destinado ao preparo do sôro contra a peste indiana, foi o inicio da grande missão de sciencia, que deveria immortalizar seu nome abençoado. Alli, como director technico, Oswald`) Cruz organizou os methodos de trabalhos sôro-therapicos, iniciou os auxiliares nos processos necessarios e chegou muito depressa, com a maior felicidade, a resultados altamente vantajosos, que se traduziram num sôro de valor curatico comparavel ao dos melhores sôros anti-pestosos, até então conhecidos.

Ao tempo, eram bem parcos os elementos de que podia dispor o mestre, para a obra de sciencia que elle idealizára: apenas tres os discipulos de então, Figueiredo de Vasconcellos, Cardoso Fontes e Ezequiel Dias, os primeiros da escola actual, solidarios com o nobre intento e possuidos de energias novas que dispensaram, annos seguidos, sempre com abnegação e alto proveito, á grandeza da obra e ao renome do mestre.

Nada importava, entretanto, ás aspirações de Oswaldo Cruz a deficiencia do inicio, que constituiu, no caso, um elemento favoravel á grandeza futura. Maior, dahi, o estimulo de quem possuia a serenidade e a firmeza de um predestinado, de quem trazia a consciencia nobilitante de uma alta missão. Tudo por fazer? Tudo seria feito sob moldes formulados pelo genio scientifico e pelo altruismo do mestre, que poderia, deste modo, fundamentar a obra imaginada na solidez de alicerces inabalaveis, constituidos pela excellencia de normas que foram a garantia de toda majestade futura.

E assim foi: a aprendizagem dos primeiros discipulos a outros indicou as vantagens da nova escola e aos poucos vieram chegando, áquelle recanto modesto de Manguinhos, levados pela curiosidade do desconhecido e animados pelos echos de um carinho incomparavel e de unia sabedoria sem artificios, outros trabalhadores esforçados, que souberam comprehender e secundar o mestre, no enthusiasmo pela causa e numa actividade de longos annos.

Foi a epocha da educação scientifica em Manguinhos, quando de Oswaldo Cruz os companheiros de então aprenderam os primordios da medicina experimental e lucraram methodos de trabalho e normas de probidade scientifica, que foram um dia a razão maior do prestigio da nossa escola.

Aos que trabalhavam naquelles dias, ao lado do querido mestre, não sobravam condições propicias, de ordem material : duas ou tres pequenas salas, apenas fornecidas do indispensavel á pesquizas elementares ; havia, porém, naquelle ambiente de fé, para garantir a evolução posterior, a supremacia de uma vontade soberana, que soube unificar es- 
forços, fundir energias e identificar objectivos. $E$ assim, sob os neIhores auspicios, começava a formar-se a escola de Oswaldo Cruz, quando feliz incidente veiu em auxilio das aspirações do mestre: Do programma benemerito de um governo daquella epocha foi parte essencial o saneamento da capital do Brazil, e, para reaiizal-o, mereceu preferencia o nome do jovem experinentador de Manguinhos. Era um chucro, segundo a ironia do tempo, em assumptos de administração publica; possuia, porém, a convicção de principios e levava para o cargo de director geral de saúde publica a intuição segura de altas responsabilidades.

O jovern inexperiente, que até então vivêra distanciado de funcções publicas, soube haver-se com firmeza, justiça e sabedoria que nobilitaram as funcções do hygienista no Brazil. Trabalhou com intensidade excepcional, em prejuizo de sua vida physica, visando satisfazer um compromisso de patriotismo, assumido no inicio de sua tarefa. $E$ venceu. De sua actividade lucrou o Paiz beneficios que não se medem e ao nome do mestre adveiu justo e compensador prestigio, todo aproveitado na realização de elevados intuitos de sciencia.

As vantagens, de ordem pessoal, consequentes do exito na campanha de saneamento do Rio de Janeiro, reverteram para Manguinhos, que constituia, na sua grandeza futura, a finalidade de todos os designios profissionaes de Oswaldo Cruz.

Ampliados agora os elementos de trabalho da nova escola, occupon-se o querido mestre, com zelo e sabedoria, da sua organisação scientifica. Foi ahi que de modo amplo se revelou a intuição do creador da medicina experimental em nossa Patria, no aproveitamento dos melhores elementos de trabalho e na selecção da capacidade technica e das aptidões especiaes de seus discipulus. Oswaldo Cruz fez de Mauguinhos, antes de tudo, uma escola de adaptação scientifica, na qual foi possivel discriminar inclinações e aproveitar intelligencias, orientando-as no sentido da maior efficacia. Conhecedor de todos os assumptos da experimentação medica, e principalmente possuidor de uma technica perfeita e de conhecimentos exactos relativos á bacteriologia, foi elle quem iniciou todos os discipulos nos processos elementares de pesquizas e quem os orientou de acordo com as habilidades de cada um. Poude ainda, nos trabalhos da sua escola, imprimir a feição de methodos individuaes valiosos, caracterisados pela minudencia de uma observação demorada e pelo rigor maximo nas conclusões possiveis.

Unico nessa phase de organisação, sua incomparavel actividade attendia á aprendizagem de todos os discipulos, a quem levava, com os melhores ensinamentos, iniciativas de trabalho e idéas novas, feliz- 
mente bem aproveitadas pelo esforço e intelligencia dos jovens pesquizadores, cujos nomes hoje referimos com justa ufania.

W Reconheceu ainda Oswaldo Cruz os beneficios de associar á organisação de sua escola a capacidade de outros pesquizadores, que haviam conquistado justa fama em alguns assumptos da experimentação medica e da biolojia geral. Seria este o meio efficaz de crear no seu Instituto, sobre os melhores fundamentos, as diversas especialidades. $\mathrm{E}$ assim o fez: Adolpho Lutz havia estabelecido as bases da zoologia medica no Brazil, em trabalhos de valor incalculavel, relativos aos assumptos mais importantes da nossa entomologia e da nossa parazitologia. Proseguia o grande sabio, com as vantagens de uma actividade rara e de uma cultura adquirida em longos annos de esforço perseverante, a enriquecer a litteratura medica nacional e a realizar estudos que aproveitaram, desde logo, ao conhecimento exacto das nossas principaes doenças, no ponto de vista etio-pathogenico, epidemiologico e prophylactico.

Faltavam, porém, á Adolpho Lutz, condiçôes propicias de uma rscula organizada, onde os beneficios de seu vasto saber pudessem aproveitar á habilitação de novos pesquizadores. Isso o comprehendeu Oswaldo Cruz, e bem depressa avaliou quanto representaria, na vida scientifica de seu Instituto, a capacidade de Lutz, cujas normas de vida profissicnal constituiam um symbolo de alta abnegação e raro desprendimento. Os intuitos e a cordialidade do fundador de Manguinhos facilmente conseguiram seduzir o sabio zoologo, que nos veiu trazer o valioso contingente de seu esforço e vasta competencia, mais prestigiando aqui os trabalhos de sua especialidade, já illustrada neste Instituto, desde a phase inicial, pelo enthuziasmo e notaveis aptidões de alguns dos melhores discipulos de Oswaldo Cruz.

Para crear e desenvolver a secção de protozoologia, ıram preferidos dois dos maiores entre os experimentadores da escola da Schaudinn. A protozoologia, agora orientada pelas vistas geniaes do grande biologo, constituia uma sciencia de largos horizontes e offerecia farta messe de noções valiosas á actividade dos pesquizadores modernos. Como sciencia abstracta, os seus problemas encerravam as grandes incognitas da biologia geral e guardavam a idea directriz que deveria aproveitar á interpretação exacta dos phenomenos vitaes e ao certo das melhores doutrinas relativas á vida universal. E como sciencia de applicação, della dependia o esclarecimento de importantes assumptos que interessavam á pathologia humana, á veterinaria, á zootechnia, á agricultura, etc. Maxime no Brazil, pela natureza tropical e intertropical de nossas doenças, era bem vasto o campo em que se deveria exercitar a habilidade de experimentadores, apparelhados pelo estudo 
da protozoologia. Havia ahi que adquirir noçỗes exactas sobre entidades morbidas peculiares a nossa Terra e havia ainda que determinar modalidades etio-pathogenicas e epidemiologicas de doenças conhecidas em outras regiões, aqui modificadas pelas influencias mesologicas.

Altos interesses da nossa cultura medica indicavam, por isso, a formação, entre nós, de uma bôa escola de protozoologia, ramo de experimentação que muito deveria aproveitar ao esclarecimento de nossa pathologia.

S. von Prowazek e Max Hartmann accederam ás instancias de Oswaldo Cruz e vieram trazer a nosso Instituto ensinamentos valiosos, que aqui perpetuam toda a grandeza daquelles espiritos geniaes e fazem parte das melhores tradições de nossa vida scientifica.

Com proveito relevante para nossa escola, tambem permaneceram neste Instituto G. Giemsa, chimico de reconhecido valor, e Hermann Duerck, anatomo-pathologista de fama mundial.

Os ensinamentos de Duerck aproveitaranı a um dos melhores discipulos de Oswaldo Cruz, a Gaspar Vianna, gloria legitima da medicina brazileira em plena juventude, e cuja vida constitue, nas recordaçòes dos que aqui lastimamos sua ausencia, um exenıplo salutar de grandeza moral e de trabalho abnegado e productivo.

Soube Oswaldo Cruz comprehender as excellencias de caracier e os primores de inteiligencia de Gaspar Vianna, a quem dispensou profundo affecto e a quem facultou os melhores elementos de acção efficiente e de prestigio profissional.

Assim agia o querido mestre na organização desta escola experimental. E visava proseguir nos mesmos intuitos, systhematizando nossos estudos de mycologia, de chimica biologica, de physiologia, de phyto-pathologia, etc., afim de mais ampliar as funcções deste Instituto e delle constituir um dos grandes factores da prosperidade economica e da cultura de nossa Patria.

Organizada a vida scientifica de Manguinhos, e systematizados nossos trabalhos nas especialidades que mais interessam á experiınentação medica e á biologia geral, não diminuiram os esforços de Oswaldo Cruz, agora tendentes a manter, entre os discipulos, o espirito de harmonia e a solidariedade de objectivos, que representaram a grande força inicial de nossa escola.

Além de que, sua actividade incomparavel e valiosa, as vantagens de seu vasto saber e rara competencia em estudos de laboratorio beneficiavam ás pesquizas de todos os jovens experimentadores de Manguinhos, que delle lucravam, nas emergencias difficeis de uma interpretação duvidosa ou nas deficiencias individuaes, a palavra de acerto e os ensinamentos necessarios á conquista da verdade exacta. 
E é de salientar, nesse ponto, a abnegação do mestre, que ao interesse collectivo e á grandeza da nova escola, na missão absorvente de educar e orientar discipulos, sempre dispensou o melhor de seu esforço, em prejuzo, ás vezes, de sua fama de pesquizador. Poderia elle, de preferencia, aproveitar em beneficio do proprio nome, ainda mais o enaltecendo, os superiores privilegios de sua rara mentalidade; julgou, porém, melhor servir a altos designios, na acção impessoal de organizar esforços, crear iniciativas, orientar intelligencias, designar methodos scientificos, proporcionar, emfim, aos experimentadores da sua escola, todos os elementos seguros de exito. E procurava occultar-se na obra realizada, ahi sempre exaltando a valia exclusiva do discipulo, de cujo successo aproveitava as mais puras e compensadoras alegrias.

Aliás esse desprendimento foi o traço mais caracteristico e nobilitante na direcção de Oswaldo Cruz, que aos companheiros de Manguinhos cedia as melhores opportunidades de efficiencia e brilho profissionaes, nos trabalhos technicos de maior relevancia e mais facil repercussão.

Muito haveria ainda que referir, nos fastos desta escola, relativo á feição scientifica de Oswaldo Cruz; quanto de melhor ahi existe, neste Instituto, nobilitante da cultura medica de nossa Patria e expressivo das energias de nossa raça, exteriorisa as abundancias de seu genio e synthetisa os elevados designios de sua vida profissional. Devemos, entretanto, nessa affirmação de um culto imperecivel, dizer do mestre o que the fôra o coração e aqui evocar aquellas valiosas confidencias de amizade, que sempre traduziram intuitos de justiça, conceitos de altruismo, aspirações de amor e de virtude, os mais puros ideaes, emfim, de uma alma voltada para o bello!

Regressaremos, desse modo, ás alegrias e ás esperanças infimitas que se foram, e vamos relembrar o querido mestre, na serenidade majestosa de quem sabia ao espirito alliar o sentimento e de quem poude retirar da bondade a grande força para as normas de justiça.

Nas reminiscencias affectuosas desta casa, bem fixados'no sentimento de quantos aqui recebémos os beneficios de seu affecto, perduram os melhores traços da individualidade moral de Oswaldo Cruz. Possuia elle o raro privilegio de se fazer, ao mesmo tempo, anado e obedecido, desse modo fundamentando a ascendencia de sua vontade soberana, em garantias de lealdade e de affeições pessoaes decisivas. Todos os funccionarios de Manguinhos, não inportava a hierarchia de posição, sabiam reconhecer no mestre o melhor dos amigos e o mais segur o amparo de todos os revéses e infortunios. E compensavam pelo esforço no trabalho e pela dedicação á obra collectiva, o conforto 
moral de uma direcção cariıhosa e tolerante, garantidora de todos os direitos, e merecedora, por isso mesmo, da observancia exacta de todos os deveres.

Nunca houve mister, ao mestre, abandonar, em defesa de principios disciplinares, o criterio "de generosidade maxima e de cordura, nas funcções de Director deste Instituto. A firmeza nas decisões e as energias necessarias á normalidade de nossus trabalhos, vinhan de Oswaldo Cruz sob as roupagens de conselhos amistosos e eram assim recebidas sem constrangimento, e melhor aproveitadas em seus nobres intuitos.

Bem reconhecia elle, $\mu$ sychologo de largo tino, us nossos defeitos, contingencia humana inevitavel; sabia, porém, neutralizal-os pelo computo com as virtudes simultaneas, e sempre concluia em beneficio do valimento maximo de seus companheiros de missão scientifica, a quem estimulava pelo apreço ao merito e pela recompensa ao esforço. Aos que viviamos a seu lado, associados no mesmo objectivo de irabalho, dispensava o melhor de sua affeicção, e desta casa, dos seus discipulos, constituiu uma segunda familia, cujos destinos vigiava com o mesmo zelo que lhe merecia o venturoso lar.

O seu convivio, ouvil-o exterionizar todas as excellencias de uma organização moral de rara belleza, delle aprender as melhores doutrinas de optimismo e receber:o influxo de sua alma enaltecida pelas maiores perfeições do sentimento) humano; lucrar tudo isso em largos annos de uma existencia de trabalho, sempre bonançosa pela influencia de seu espirito protector, foi o supremo beneficio de sell affecto e constituiu a maior ventura de nossos dias.

E quantos de seus discipulos the devemos, de modo exclusivo, a felicidade do proprio destino profissional ? Quantos para aqui viemos, numa phase de incertezas e vagas aspirações, encontrar na longanimidade de Oswaldo Cruz a directriz exacta de um futuro propicio?

E quantos delle lucrámos, naquelles dias de uma mocidade exhuberante e passivel de orientações diversas, o apoio decisivo e opportuno, que nos foi o grande bem e nos desviou, talvez, de todo o mal?

Não só incalculaveis beneficios de trabalho devemos ao carinho dc querido mestre; muitos dos que hoje veneramos sua memoria, tivemos a rara ventura de completar nossa formação moral sob a influencia decisiva daquelle espirito magnanimo, que poude modificar, sempre aperfeiçoando, o caracter e o sentimento de alguns dos seus melhores discipulos. E nada resistia á grande força de seu exemplo e á segurança de seus principios; além de que, educava pelo coração, 
fallando ás consciencias aquella linguagem sempre singela e de bellezas infinitas, que fascinava e convencia, orientando para o bem.

E foi assim annos seguidos de nossa vida collectiva, durante os quaes todos os primores que enalteciam o sentimento do querido mestre, todos os encantos que exaltavam sua alma majestosa, valeram-nos, a seus discipulos, as nossas melhores alegrias, e constituiram o grande patrimonio moral de nossa escola.

Nem findaram, com a vida do mestre, os beneficios de sua acção: sobre esta casa, hoje confiada a seus manes protectores, poude Oswaldo Cruz, ao morrer, projectar a grande sombra de seu prestigio, e garantir assim a perpetuidade de sua obra meritoria. E, aliás, foram sempre esses os augurios de seu optimismo, quando affirmava, em ccntradicção com o sentir de todos nós, ser possivel proseguirmos na mesma jornada de trabalho, embora della ausente, um dia, o grande espirito que a guiava. Tal a confiança do mestre no animo resoluto e na solidariedade dos discipulos bem-amados! Taes as esperanças de uma alma que a outras almas procurou communicar nobres designios!

E cumpre que assim seja; cumpre que elle, morto, continu: a dirigir os que vivemos, na permanencia daquellas normas de trabalho, que fizeram o renome de nossa escola, e daquelles elevados ideaes de sciencia, que fizeram a gloria imperecivel de Oswaldo Cruz.

Aqui o nosso adeus ao melhor dos amigos e ao maior dos mestres! Quiz elle, bem inopinadamente, abandonar a casa onde viveu e apostolou. E daqui se foi para muito longe, para o futuro de uma nacionalidade, enaltecendo-a, symbolisar o heroismo do trabalho, a força e a proficuidade de principios inabalaveis, a maior grandeza das acções humanas. Levam-no, para honra de nossa épocha, os echos de uma redempção profissional $\mathrm{e}$ as bençãos de uma Patria agradecida!

Instituto Oswaldo Cruz, Julho de 1917.

C. C. 